\title{
Enunciación
}

\section{Comunicación no verbal: las voces del cuerpo detrás de los cristales}

\author{
Non-verbal communication: the voices of the body behind glass \\ Evelyn Gabriela Buitrago Espitia*
}

\begin{abstract}
Resumen
Este artículo es resultado de la investigación titulada "Comunicación no verbal y educación". Su objetivo es describir y analizar dicha comunicación en las interacciones virtuales durante la crisis covid-19, tiempo en el que las interacciones escolares cambiaron radicalmente y en las que se anula casi totalmente la comunicación no verbal. Para el diseño metodológico se recurrió a un enfoque cualitativo hermenéutico-fenomenológico en el que priman la comprensión y la interpretación de situaciones emergentes, como lo es la comunicación a través de los cristales, que se ha dado en la educación durante la pandemia. El corpus se obtiene de grabaciones de clases en línea, de entrevistas semiestructuradas y cuestionarios aplicados a profesores y estudiantes universitarios. El análisis del corpus se hace con categorías de la comunicación no verbal como: kinésica, cronémica, proxémica, paralenguaje y factores ambientales. Los referentes teóricos articulan los aportes de la comunicación no verbal de diferentes autores con las estéticas prosaicas de Mandoki (2006). De igual forma, en el contexto de la comunicación no verbal en tiempos de pandemia, nos apoyamos en los aportes teóricos de la cibercultura y de las hipermediaciones con autores como Crystal (2002), Lévy (2007) y Scolari (2008). El análisis de los resultados evidencia que en este contexto se da poca relevancia a la comunicación no verbal en los procesos de enseñanza/aprendizaje. Así, esta investigación permite afirmar que es necesario recuperar las voces del cuerpo (schêmata) que se han perdido en estas interacciones, como una apuesta política necesaria e importante en prácticas futuras.
\end{abstract}

Palabras clave: comunicación no verbal, educación, pandemia, proxémica, factores ambientales, ciberespacio, TIC.

\begin{abstract}
This article is the result of research entitled Non-verbal communication and education. Its objective is to describe and analyze said communication in virtual interactions during the Covid-19 crisis, a time in which school interactions changed radically and in which non-verbal communication was 'almost' completely annulled. For the methodological design, a qualitative hermeneutical-phenomenological approach was used in which the understanding and interpretation of emergent situations such as communication through crystals, which has occurred in education during the pandemic, prevail. The corpus is obtained from online class recordings, semi-structured interviews and questionnaires applied to university professors and students. The analysis of the corpus is done with categories of non-verbal communication such as: kinesic, chronic, proxemic, paralanguage and environmental factors. Theoretical referents articulate the contributions of non-verbal communication of different authors with the prosaic aesthetics of Mandoki (2006). Similarly, in the context of non-verbal communication in times of pandemic, we rely on the theoretical contributions of cyberculture and hypermediations with authors such as Crystal (2002), Levy (2007) and Scolari (2008). The analysis of the results shows that in this context there is little relevance to non-verbal communication in the teaching-learning processes. Thus, this research allows us to affirm that it is necessary to recover the voices of the body (schêmata) that have been lost in these interactions, as a necessary and important political commitment in future practices.
\end{abstract}

Keywords: non-verbal communication, education, pandemic, proxemics, environmental factors, cyberspace, TIC.

* Licenciada en Humanidades y Lengua Castellana de la Universidad Distrital Francisco José de Caldas. Integrante del semillero de investigación Hermeneia. Correo electrónico: egbuitragoe@correo.udistrital.edu.co

Cómo citar: Buitrago, E. (2021). Comunicación no verbal: las voces del cuerpo detrás de los cristales. Enunciación, 26(1), 57-73. http://doi.org/10.14483/22486798.17588 Artículo recibido: 09 de abril de 2021; aprobado: 16 de julio de 2021 


\section{Introducción}

En época de pandemia por covid-19 nos hemos visto en la obligación de distanciarnos y comunicarnos a través de aparatos tecnológicos; por ello, se ha percibido la ausencia de la comunicación no verbal $(\mathrm{CNV})$ que está presente en el mundo de la vida cotidiana. No poder recurrir a este tipo de comunicación repercute en todo el sistema educativo, en particular en las clases en línea. En la mayoría de los casos los profesores no saben si están transmitiendo de manera adecuada sus conocimientos, ya que no hay alguna señal de gusto o desagrado, todas las señales no verbales se han ido. Por su parte, los estudiantes no cuentan con la proxémica del docente, su espacio está limitado por la división entre una pantalla y otra, ya no pueden alistar sus cuadernos para que el maestro se percate de que la clase terminó; los trabajos en grupo fueron reemplazados por exposiciones virtuales. De allí surgió la necesidad y el interés de esta investigación.

El enfoque utilizado en este estudio es cualitativo, porque permite acercarnos a la realidad de las interacciones en línea y analizar la comunicación no verbal en tiempos de crisis como un factor determinante en la cotidianidad. El diseño de nuestro trabajo es el hermenéutico-fenomenológico, pues, tal como lo mencionan Gadamer (1984) y Van Manen (2003), este diseño es apto para aplicar en el campo educativo, ya que se centra en los encuentros humanos, en el sano cuestionamiento y en la reflexión de las prácticas pedagógicas. El corpus se obtuvo de clases grabadas, entrevistas semiestructuradas y cuestionarios abiertos a profesores y estudiantes de la Licenciatura en Humanidades y Lengua Castellana (LHLC) de la Universidad Distrital Francisco José de Caldas, ubicada en Bogotá (Colombia).

Para analizar el corpus tomamos las siguientes categorías de la CNV: kinésica, cronémica, proxémica, paralenguaje y factores ambientales, abordadas desde los referentes teóricos tomados principalmente de Poyatos (1994), Goffman
(1971), Cooper (1988) y Mandoki (2006). También, acudimos a los aportes de la cibercultura y de las hipermediaciones con autores como Crystal (2002), Lévy (2007) y Scolari (2008), pues nuestro propósito es situar el contexto de la comunicación no verbal en tiempos de pandemia, para desde allí usar las tecnologías de la información y la comunicación (TIC) con la finalidad de encarar y superar las dificultades comunicativas durante y pospandemia. A manera de conclusión y resultados preliminares de este trabajo, señalamos la necesidad de que todos los profesores y estudiantes conozcan su propia CNV, sean conscientes de cómo habla su cuerpo, qué mensajes envía, cuáles son sus gestos y expresiones más característicos. Todo esto con el fin de potenciar aún más las interacciones humanas a través de las pantallas.

\section{Comunicación no verbal}

La CNV hace referencia a las voces del cuerpo o a lo que los griegos Ilamaban la schêmata- $\sigma \chi \eta \dot{\mu} \mu \alpha \alpha$. La schêmata contempla esos sonidos del cuerpo que funcionan como vehículo, recipiente y mensaje en sí mismos; a su vez, estos manifiestan, expresan, gritan y callan. Concepto fundamental porque, según Aristóteles (1975, 1990), los hombres adecúan su schêmata dependiendo de la intención de su discurso. Autores como Mehrabian (1972), Birdwhistell (1970), Davis (2007) y Castañer (2012) indican que los mensajes no verbales tienen más peso en la interacción que los mensajes verbales, pues, sin esta comunicación el hombre, en este caso, el docente o el estudiante, se presenta únicamente con su desnudez lingüística. En cuanto al ámbito educativo, Cooper (1988) menciona que este tipo de comunicación es importante en el aula porque mejora el aprendizaje cognitivo y afectivo, ya que los maestros suelen usar inconscientemente mensajes no verbales para apoyar y animar la clase. Así mismo, estos elementos constituyen la imagen del docente, ayudan a identificar sus expectativas, reducen las barreras y aumentan la participación. 
Ahora, sobre las categorías no verbales que orientan esta investigación tenemos como primera categoría a la kinésica. Poyatos (1994) afirma que consiste en "el estudio sistemático de los movimientos corporales no orales, de percepción visual, auditiva o tangible, que aislados o combinados con la estructura lingüístico-paralingüística poseen valor expresivo en la comunicación interpersonal" (p. 733). En términos de Mandoki (2006), esta hace referencia a la cinética somática que analiza la ligereza o pesadez de los movimientos corpóreos. Por ejemplo, no nos movemos igual cuando estamos bailando que en una caminata.

En segundo lugar, abordaremos la cronémica. Dicha categoría estudia la conceptualización, estructuración y el manejo del tiempo como elemento psicológico y social (Ferrero y Martín, 2013). En cuanto a su funcionamiento en el aula, Cooper (1988) plantea que se refiere a la cantidad de tiempo en que el profesor pregunta y responde, cuántos temas decide explicar en una clase y cuánto demora en cada uno, en qué momento del día los estudiantes participan o guardan silencio.

En tercer lugar, analizamos la proxémica desde importantes aportes de Mandoki (2006). En este concepto referenciamos cuatro tipos de proxémica: acústica, somática, escópica y léxica. La primera describe la distancia que el volumen de la voz determina entre un emisor y su receptor, por ejemplo, los profesores con su voz deben proyectar su liderazgo en relación con los estudiantes. La segunda contempla el espacio corporal que se tiene respecto a los demás: en las instituciones educativas se establece una organización de acuerdo con la edad, género o grupos. También se ejerce proxémica somática en relación con el maestro: "los más aplicados se sientan adelante y los más rebeldes atrás" ${ }^{\prime}$. La tercera analiza la distancia que se impone a través de artefactos o usos del espacio. Por ejemplo, en los colegios el uniforme establece

1 La proxémica somática es similar a la categoría recinto de Goffman (1971), porque considera que hay auxilios físicos para demostrar la distancia corporal, por ejemplo, en el aula de clase la posición de las sillas reclama una distancia ante el profesor y los demás estudiantes. una distancia entre la casa y la escuela, hace unos años era aceptado que los profesores se vistieran informales porque minimizaba la proxémica que debían tener los alumnos. La última determina la distancia que debe tomar el receptor frente a su emisor por medio del volumen de la voz o del tipo de lenguaje que se utiliza; algunos profesores Ilaman a los estudiantes por su apellido, otros sitúan algún tipo de distancia léxica al referir "usted", mientras que con "tú" se acercan.

En cuarto lugar, se encuentra el paralenguaje, investigado por primera vez por Trager (1958), quien planteó que esta disciplina se ocupaba de las vocalizaciones y las cualidades de la voz. Además, le dio un carácter holístico a la comunicación porque consideraba que el lenguaje y el paralenguaje son inseparables, es decir, su estudio individual es imposible. Mandoki (2006), en cambio, reconoce algunas modalidades de la voz que tienen un peso importante en la producción de esta categoría: la enfática acústica hace referencia al despliegue que le damos a la voz para enfatizar en determinada situación; en otras palabras, jugar con nuestros tonos. Este fenómeno se denomina fluxión acústica, y "se presenta en la exhibición o contención sonora que emite el sujeto en una situación determinada" (Mandoki, 2006, p. 57). Por ejemplo, los profesores constantemente realizan fluxiones en su voz: las docentes de preescolar tienen una fluxión en particular para atrapar a los niños, mientras que los maestros de estudiantes mayores usan énfasis más "serios".

Finalmente, tendremos en cuenta en esta investigación, los factores ambientales que refieren al entorno psicológico y físico en que se produce la interacción comunicativa. Goffman (1956) lo Ilama el medio (setting) que "incluye el mobiliario, el decorado, los equipos y otros elementos propios del trasfondo escénico, que proporcionan el escenario y utilería para el flujo de acción humana que se desarrolla ante, dentro o sobre él" (p. 34). Por su parte, Mandoki (2006) menciona que al momento de preparar el setting las personas utilizamos 
de acuerdo con el contexto la enfática escópica ${ }^{2}$ que se relaciona con la marcación que es posible evidenciar en el vestuario, peinado, maquillaje o accesorio como parte de la escenificación; por ejemplo, una bailarina enfatizará en su vestimenta o maquillaje.

A su vez, forma parte del marco teórico la idea de ciberespacio y cibercultura pues, aunque hemos evidenciado que la CNV está presente en todas las manifestaciones de la vida cotidiana; lo que admiramos con la vista, emanamos con el cuerpo, recordamos con el olfato, ocultamos con los silencios o demostramos con "el envoltorio". Es necesario situar esta investigación en el contexto de la virtualidad que caracteriza la pandemia covid-19. Por tanto, es prudente reconocer estos conceptos, entender cuál es su función en el ámbito educativo y social, para finalmente examinar ¿cómo se articula el ciberespacio y la cibercultura con la CNV? Y pensar, ¿de qué manera la CNV está presente en el ciberespacio? (Si es que lo está).

De acuerdo con lo anterior, Lévy (2007) afirma que las tecnologías creadas por el hombre se encuentran en el ciberespacio; este es un espacio de comunicación abierto que permite la interconexión entre ordenadores, crece en la cibercultura y, además es el entorno de la inteligencia colectiva. Por su parte, Scolari (2008) expone que el ciberespacio "no solo es el lugar de las comunicaciones sino también un generador de discursos, un espacio enunciativo donde una variedad de intereses declama sus orígenes, mitos y tendencias futuras" (p. 137).

Ahora, la educación mediada por la cibercultura y el ciberespacio tiene diferentes ventajas. Primero, es mucho más rápido y fácil renovar los saberes. Segundo, el conocimiento siempre está en transacción, por lo tanto, no deja de crecer. Tercero, el ciberespacio soporta varios tipos de tecnologías

2 Para entender la diferencia entre proxémica escópica y enfática escópica daremos un ejemplo; si nos situamos en un colegio, sabemos que si no somos estudiantes no podremos ingresar (está proxémicamente limitado para una población que son los alumnos) porque hay una proxémica escópica que nos lo dice. Ahora bien, escópicamente este lugar tiene unas reglas como lo es el porte de un uniforme, esa es la enfática escópica del colegio, hay un énfasis en la vestimenta. intelectuales que amplían, exteriorizan y modifican algunas funciones de los humanos. Por último, facilita el aprendizaje en red, que cambia totalmente los roles de los participantes, pues el hipertexto tiene tal poder para que el autor sea un lector, un crítico con sus comentarios, un bibliotecario al poner etiquetas, un diseñador al crear imágenes, un editor o un productor (Lévy, 2007; Scolari, 2008).

Así, conocer el despliegue de la cibercultura y del ciberespacio es fundamental a la hora de describir las señales no verbales que se encuentran en el aprendizaje vía remota, pues los estudiantes pueden caracterizar diferentes roles, abrir hipervínculos que los lleva a imágenes, juegos, podcast, videos, conferencias, tutoriales o películas. En cada una de estas maneras de adquirir conocimiento o de simplemente navegar por la red, hay múltiples formas de traducir los sistemas no verbales que tenemos en las clases presenciales. Por eso, el mundo de la cibercultura, del ciberespacio, de internet no está totalmente fuera de la $\mathrm{CNV}$, ya que esta comunicación se presenta de diversas maneras.

Además, antes de considerar la comunicación que se da en la virtualidad como una versión empobrecida del lenguaje tradicional, se debe reconocer que el uso de internet y de las TIC ha dado cuenta de la capacidad de las personas para adaptarse a las nuevas formas para interactuar; por eso internet no está alejado lingüísticamente de otras formas de discurso. Estamos de acuerdo con Crystal (2002) en que la tecnología, internet o la red no representan una amenaza para el discurso oral y escrito porque la ciberhabla no es equivalente a ninguno, sino que tiene propiedades de ambos. Más bien es una revolución probablemente lingüística que utiliza el medio electrónico para comunicar de otras maneras que son fundamentalmente distintas de las que encontramos en otras situaciones semióticas.

\section{Metodología}

El enfoque de esta investigación es cualitativo, ya que resulta imprescindible analizar lo cotidiano como un factor determinante en la comprensión 
e intervención de la realidad a investigar, que en nuestro caso es la CNV, pandemia y TIC. En ese sentido, el diseño metodológico corresponde al hermenéutico-fenomenológico, por cuanto permite caracterizar las señales no verbales en las clases remotas con el fin de comprender el problema y repensarlo a partir de nociones propias. En este trabajo se toma como corpus a algunos profesores y estudiantes de la Licenciatura en Humanidades y Lengua Castellana de la Universidad Distrital Francisco José de Caldas, del semestre 2020-1. Para recolectar los datos se utilizaron cuatro herramientas: observación y descripción de clases grabadas, entrevistas y cuestionarios.

\section{Herramientas para la recolección de los datos}

En el presente apartado se exponen las herramientas de recolección de datos: observación y descripción de clases grabadas, entrevistas y cuestionarios. Estas serán analizadas a la luz de las categorías no verbales: kinésica, cronémica, proxémica, paralenguaje y factores ambientales. También, tendremos en cuenta el uso de las TIC, para encontrar algún tipo de traducción semiótica a estas categorías y, por último, analizaremos cómo se percibe la CNV en la comunidad educativa.

\section{La observación}

La primera herramienta que utilizaremos para obtener los datos investigativos es la observación de clases grabadas pues, en palabras de Hernández et al. (2014), observar en la investigación cualitativa significa ir más allá de la vista y activar cada uno de los sentidos. Las observaciones recuperadas para este trabajo son videos de ocho clases grabadas por Google Meet (por lo cual la investigadora no interactuó con los profesores ni con los estudiantes). Para la observación de las clases fueron seleccionados cuatro docentes y los estudiantes asistentes a sus clases (en promedio son 23). Así mismo, con el fin de caracterizar las diversas maneras en que se presentan las señales no verbales en las clases de la licenciatura, se eligieron asignaturas de los diversos semestres y componentes establecidos en el plan de estudios: semiodiscursivo, ético-humanístico, investigativo-pedagógico y electivas.

Por otro lado, para analizar y sistematizar los datos, se recurre metodológicamente a asignar un numero para cada clase 1, 2, 3, 4 o 5 (las clases 1 y 2 son dictadas por profesores, y las clases 3, 4 y 5 por profesoras) y la letra $A$ o $B$, a cada una de sus grabaciones. Por ejemplo, la case Antropología, subjetividad y escuela del componente ético-humanístico tiene dos grabaciones; la clase A del 05 de mayo de 2020 y la clase B del 16 de julio de 2020. Para nuestro análisis es muy importante asignar una letra que diferencie cada grabación. Dicha información la podemos observar en la tabla 1.

Además, a fin de comprender e interpretar los datos recogidos de la observación de las clases grabadas, buscamos la forma de categorizarla de acuerdo con nuestro objetivo: "caracterizar y fortalecer la comunicación no verbal de las interacciones virtuales universitarias (profesor/estudiante) en época de pandemia de la Licenciatura en Humanidades y Lengua Castellana de la Universidad Distrital Francisco José de Caldas". Se pretende analizar cómo surgen las categorías no verbales: kinésica, cronémica, proxémica, paralenguaje y factores ambientales en las clases virtuales; y si estas categorías tienen cierta trasposición en la virtualidad. Es decir, si de alguna manera las categorías forman parte de algún proceso de adaptación a las TIC. Para dicho propósito se elaboró la tabla 2.

\section{La entrevista}

La siguiente herramienta para la recolección de datos es la entrevista, pues será útil para corroborar o diferir los resultados de la observación. Kvale (2011) afirma que la entrevista en la investigación cualitativa tiene como propósito que las personas entrevistadas describan cómo experimentan y 
Tabla 1. Clases grabadas

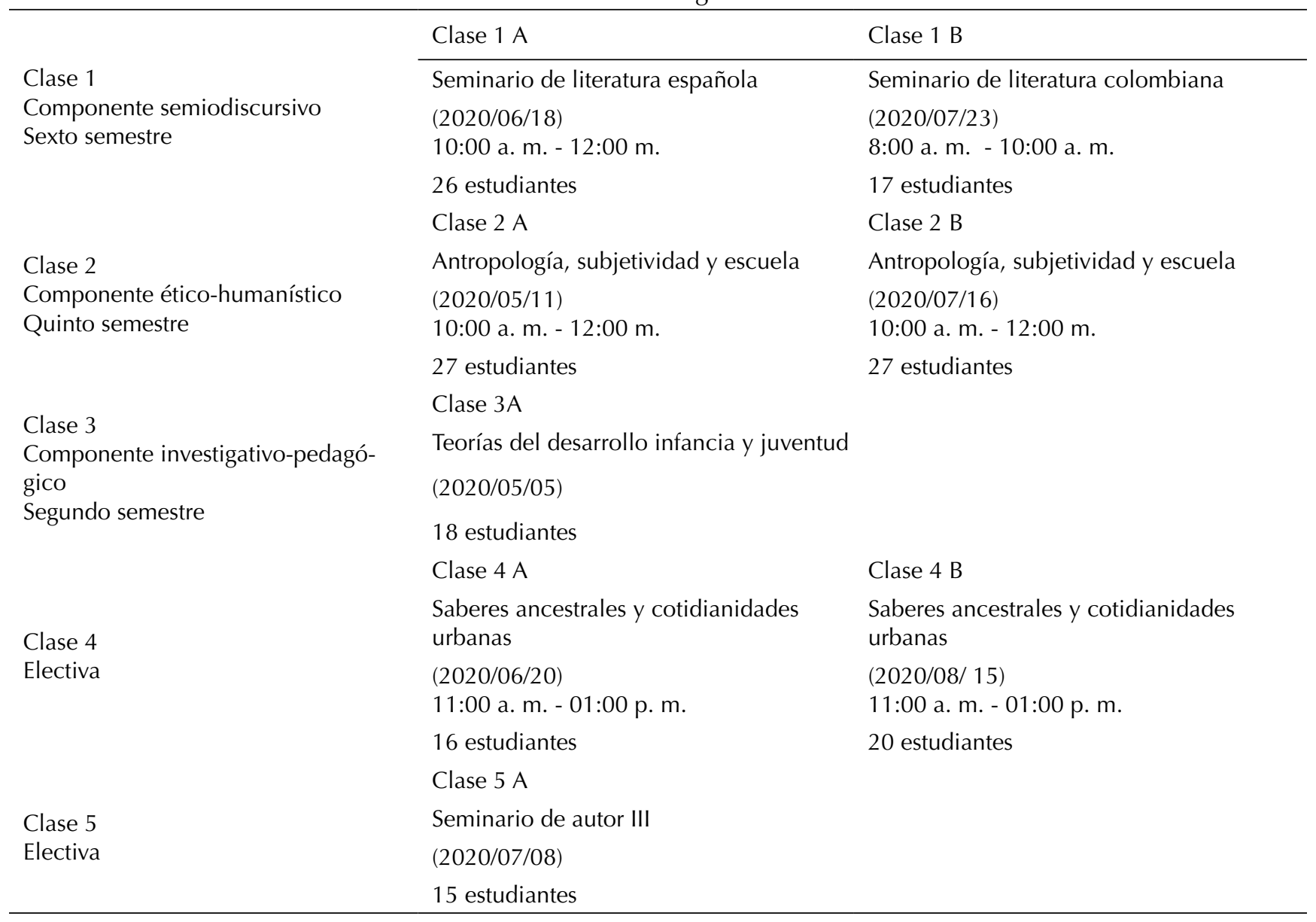

Fuente: elaboración propia.

entienden su mundo vivido, con el fin de interpretar de manera fehaciente los fenómenos descritos. Las entrevistas de la investigación fueron abordadas desde las categorías no verbales: kinésica, cronémica, proxémica, paralenguaje, factores ambientales y la mediación de las TIC. Se entrevistaron los cuatro profesores que cedieron sus clases grabadas para la observación, y para obtener la perspectiva de los estudiantes se realizaron cuatro entrevistas a algunos alumnos asistentes. Todas las entrevistas tenían la misma finalidad: caracterizar las interacciones que se dan en pandemia, específicamente con el uso de la CNV.

Respecto a las cuatro entrevistas para docentes se tuvo en cuenta la edad, pues consideramos que en el contexto de la pandemia ha sido determinante el factor de la edad a la hora de acoplarse a las clases virtuales-remotas y, así mismo, Ilevar las señales no verbales a estas interacciones. Además, como en la observación de las clases, se consideró que los profesores impartieran clases en diferentes componentes para triangular los datos que pudieran arrojar las demás herramientas de recolección. En la tabla 3 aparecen las preguntas que formaron parte de la entrevista.

En cuanto a los estudiantes seleccionados para la entrevista, nos acercamos a aquellos que representaran la diversidad de semestres, es decir: segundo semestre, cuarto semestre, sexto semestre y octavo semestre. Como se demuestra en la tabla 4, 
Tabla 2. Descripción de las clases grabadas

\begin{tabular}{lll}
\hline \multicolumn{1}{c}{ Clase 1A } & \multicolumn{1}{c}{ Materia } & \multicolumn{1}{c}{ Fecha y hora } \\
\hline Categoría no verbal & Aspecto & Descripción \\
Kinésica & $\begin{array}{l}\text { Lenguaje facial } \\
\text { Lenguaje corporal } \\
\text { Lenguaje postural } \\
\text { Conducta táctil }\end{array}$ & \\
Cronémica & Tiempo destinado a las actividades \\
propuestas & \\
Comentarios & Tiempo dialógico \\
Proxémica & Tiempo para preguntar y/o contestar \\
Comentarios & Uso del espacio personal \\
Paralenguaje & Desplazamiento \\
Comentarios & Tono de voz \\
Factores ambientales & Fuevos sonidos \\
Comentarios & Aspecto físico \\
Uso de las TIC & Objetos usados \\
\hline
\end{tabular}

Fuente: adaptado del protocolo "Descripción no verbal del docente" que plantean Ferrero y Martín (2013).

Tabla 3. Entrevista a profesores

¿Cuál es su edad?

Cuando dicta clases, ¿utiliza miradas, gestos, sonrisas o movimientos para enfatizar sus mensajes?

En cuanto al tiempo, ¿sus clases duran lo mismo o tienden a terminar antes?

¿Cuánto tiempo cree que los estudiantes toman la palabra?

¿Los estudiantes encienden la cámara cuando hablan?

¿Considera que no ver a los estudiantes afecta el proceso de enseñanza?

¿Cómo controla los silencios en las clases en línea?

¿Cómo es su preparación para dictar clases? ¿Se prepara físicamente como lo hacía en la presencialidad?

En cuanto al uso de las TIC, ¿qué herramientas o plataformas utiliza? ¿Cómo ha sido este proceso?

¿Considera que la comunicación no verbal es importante en las clases en línea?

¿Qué recomendaría para mejorar la comunicación no verbal de las clases en línea?

Fuente: elaboración propia 
este criterio permite reconocer diferentes perspectivas de los estudiantes sobre la CNV. Por ejemplo, los alumnos de segundo semestre que ingresaron a la universidad en el contexto de la pandemia no han asistido a las clases presenciales, así que su experiencia en cuanto el uso de la CNV en clases tiene otras características.

\section{El cuestionario}

Desde el punto de vista de Álvarez-Gayou (2003), el cuestionario es una de las pocas herramientas para obtener información sin estar cara a cara con la persona interrogada; por tanto, mediante este recurso puede interrogarse a más personas. Así, elegimos el cuestionario abierto a través de Google Forms, porque permite abarcar diferentes percepciones de profesores y estudiantes (no solo de los participantes de las clases grabadas) sobre el problema a investigar, sin necesidad de estar espacialmente con ellos o realizar llamadas telefónicas/en línea y plantear entrevistas a fondo que consumen mucho más tiempo de análisis. De esta manera, conocimos mucha información que los participantes de las entrevistas se reservaban al tener contacto con la investigadora, además, como en el caso de las entrevistas, se accedió a estudiantes de diferentes semestres y, en el caso de los profesores, de diversas edades. La muestra la constituyen profesores (20) y estudiantes (90) ya que, en el caso de estos últimos, no estaba al alcance de la investigación obtener las respuestas de más de 500 estudiantes que forman parte de la licenciatura. En las tablas 5 y 6 se reflejan las preguntas que formaron parte del cuestionario para docentes y estudiantes.

\section{Resultados y análisis}

\section{Kinésica}

Como se mencionó en el marco teórico, la kinésica engloba los elementos ligados a movimientos corporales como los gestos, la postura corporal y, en resumen, todo lo que trasmitimos con nuestro cuerpo. En cuanto a los profesores, diremos que en las clases grabadas se evidenció que todos activan su cámara (menos la profesora de la clase 5A seminario de autor III por fallas técnicas). Por ello, observamos que emiten diferentes gestos, asienten o niegan, todos mueven las manos para explicar y apoyar sus mensajes verbales, algunos sonríen reiteradamente como si estuvieran junto a sus estudiantes. Cada acción kinésica de los profesores refleja, desde la perspectiva Mandoki (2006), la ligereza o pesadez de sus movimientos, algunos se ven tensos, otros parecen totalmente relajados. Dicha información la podemos proyectar en la pregunta realizada a profesores en el cuestionario de Google Forms (ver figura 1).

Tabla 4. Entrevista a estudiantes

\section{¿Qué semestre se encuentra cursando?}

¿Sus profesores utilizan miradas, gestos, sonrisas o movimientos para enfatizar sus mensajes? ¿Esto influye en su disposición en clase?

En cuanto al tiempo, ¿las clases duran lo mismo o tienden a terminar antes?

¿Usted enciende la cámara cuando habla?

¿Considera que el tono y volumen de la voz de los profesores influye en que pueda prestar atención en clase?

¿Usted toma la palabra cuando se presentan silencios en clase? ¿Los ignora? ¿Escribe en el chat?

¿Cuál es su preparación para asistir a clases? ¿Se prepara físicamente como lo hacía en la presencialidad?

En cuanto al uso de las TIC, ¿considera que los docentes utilizan las TIC de manera adecuada?

¿Considera que la comunicación no verbal es importante en las clases en línea?

¿Qué recomendaría para mejorar la comunicación no verbal de las clases en línea?

Fuente: elaboración propia 
Tabla 5. Cuestionario a profesores

Edad

Género

¿En qué lugar suele dar sus clases?: cocina/estudio/sala/comedor/otro

¿Cómo da sus clases?: sentado/caminando de un lado a otro/de pie/otro

¿Realiza otras actividades mientras dicta clase?: sí/no

Si la respuesta anterior fue afirmativa, indique cuál:

¿Cuánto tiempo enciende la cámara en clase?: nunca/solo cuando habla/toda la clase

Desde su perspectiva, ¿no ver a los estudiantes afecta el proceso de enseñanza?: sí/no

Explique la respuesta anterior:

¿Es consciente de su gesticulación, movimientos corporales, tono de voz y ritmo del discurso cuando imparte sus clases?:

sí/no/no lo sé

¿Suele volver a las grabaciones de sus clases para ver su gesticulación, movimientos corporales, tono de voz y ritmo del discurso?: sí/no

¿Cree que el transcurrir del tiempo es diferente en la virtualidad que en la presencialidad? Explique por qué

¿Qué tipo de ropa utiliza para dar clase?

¿Utiliza accesorios en las clases en línea? ¿Cuáles? (aretes, anillo, labial, auriculares)

¿Cuál plataforma usa frecuentemente para dar clases?: Zoom/meta/Skype/Goog/e Hangouts/Microsoft Teams/otra

¿Con cuáles aplicaciones crea contenido didáctico para sus clases?: Power Point/Kahoot/Canva/Pixlr/otra

¿Qué es lo que más extraña de las clases presenciales?

¿Considera que la comunicación no verbal tiene importancia en las clases en línea?: sí/no/no conozco la comunicación no verbal

Explique la respuesta anterior:

¿Qué recomendaría para mejorar la comunicación no verbal de las clases en línea?

Fuente: elaboración propia.

Tabla 6. Cuestionario a estudiantes

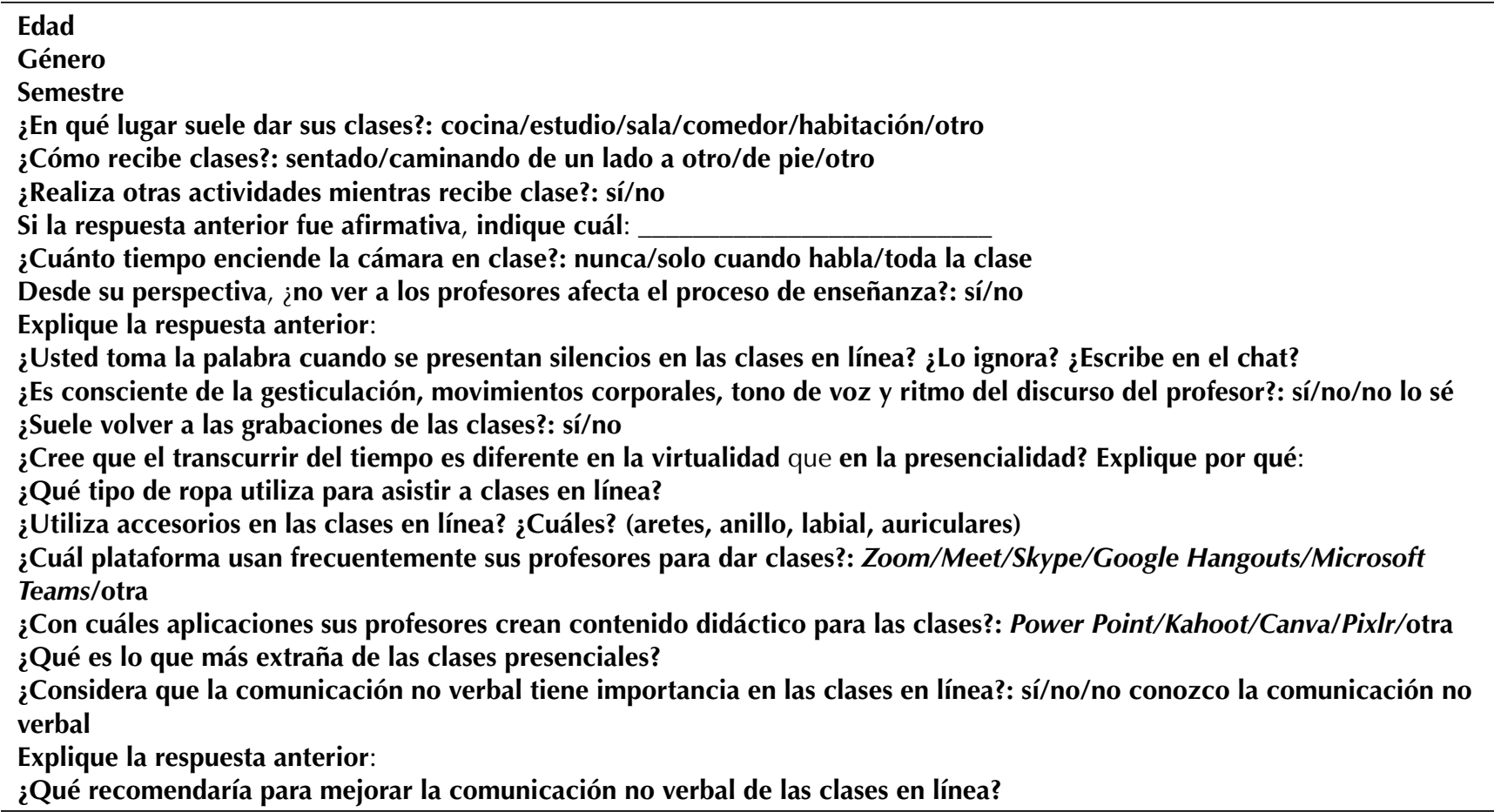

Fuente: elaboración propia 
- Toda la clase - Solo cuando habla $\approx$ Nunca

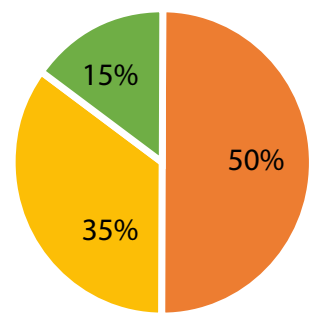

Figura 1. Pregunta para profesores: ¿Cuánto tiempo enciende la cámara en clase?

Fuente: elaboración propia.

Bayes (1970) y Gafner (1977) consideran que cuando los maestros son kinésicamente activos los estudiantes no se aburren, prestan atención y participan en clase. Dicha afirmación pudo corroborarse al analizar las respuestas de los profesores, pues, para la mayoría, realizar movimientos corporales y faciales es crucial para logar la atención de los estudiantes; algunos de esos movimientos son involuntarios y otros voluntarios

Me acerco hacia el lente, abro los ojos, me retiro, muevo el brazo, me recuesto sobre las manos y cada uno de esos movimientos (unos conscientes y otros no tanto) cumplen una función comunicativa, pero hago movimientos conscientes tratando de hacer que la cámara me ayude a que lo que hago signifique algo más para los estudiantes. (Entrevista profesor 1, 03 de noviembre, 2020)

Ahora bien, esta categoría es prácticamente nula en los estudiantes porque la mayoría de veces no activan su cámara por diferentes razones: sienten vergüenza, creen que es un espacio íntimo, no es necesario para ellos o no tienen cámara; excepto en la clase 3B (Saberes ancestrales y cotidianidades urbanas), donde casi todos los alumnos encendieron la cámara debido a que la dinámica de la clase lo exigía, y a que la evaluación final consistía en realizar un molinete y mostrar por medio de la cámara el resultado. Sin embargo, como se evidencia en la figura 2, que plasma las respuestas del formulario de Google Forms, un gran porcentaje de los estudiantes no enciende la cámara en clase y un $43 \%$ solo cuando habla, pero esta información no tuvo relación con los datos que se arrojaron en la observación de las clases grabadas porque, como se ha dicho, solo en una clase las cámaras estuvieron encendidas.

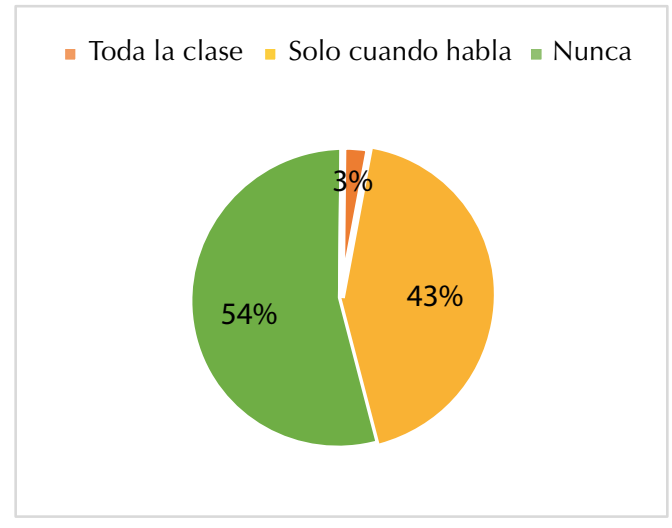

Figura 2. Pregunta para estudiantes: ¿Cuánto tiempo enciende la cámara en clase?

Fuente: elaboración propia.

Por otro lado, al cruzar los datos de las clases grabadas con las entrevistas y cuestionarios, encontramos que, sobre la categoría kinésica para la mayoría de los profesores no ver a los estudiantes afecta el proceso de enseñanza, pues como lo menciona Cooper (1988), no se tiene ese contacto humano que brinda el aula. También hallamos que los docentes encienden la cámara porque consideran que pueden recibir una mayor atención. Esta información se pudo constatar con la percepción que tienen los estudiantes sobre la importancia de ver a los profesores; muchos afirmaron que era más fácil aprender cuando los docentes activaban su cámara, aunque nunca observaban de forma detallada sus gestos o movimientos. La figura 3 recopila dicha información. 


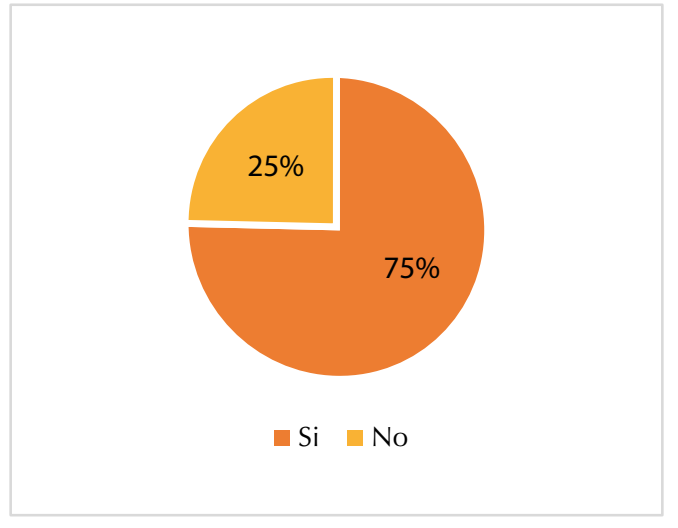

Figura 3. Pregunta para profesores: ¿No ver a los estudiantes afecta el proceso de enseñanza?

Fuente: elaboración propia.

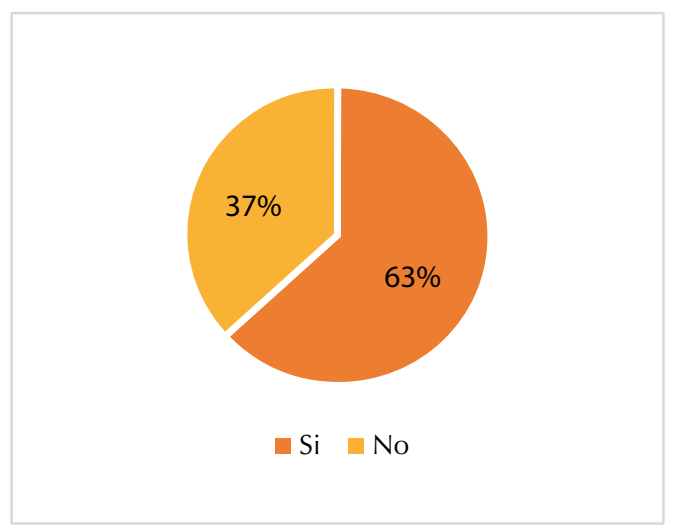

Figura 4. Pregunta para estudiantes: ¿No ver a los profesores afecta el proceso de enseñanza?

Fuente: elaboración propia

\section{Cronémica}

La siguiente categoría que abordaremos en este análisis es la cronémica. Recordemos que esta estudia la relación que tenemos con el tiempo. En época de pandemia, los segundos y los minutos parecieran seguir pasos de tortuga, pero para otros las horas y las tardes se desvanecen en un solo parpadeo. Las clases en línea no están exentas de dicha dualidad, los profesores afirman que el tiempo pasa tan rápido que pareciera ser más corto.
Además, el trabajo se triplica y estar frente a una pantalla todo el día no permite disfrutar los pocos momentos de descanso se puedan tener. El trabajo para los maestros es arduo, detrás de la pantalla hay horas de planeación de clase, atención a los estudiantes, lectura de correos, revisión de trabajos, miles de intentos por innovar que consumen todo el tiempo. No hay tiempo para la distracción y a diferencia de los estudiantes, los profesores no realizan otras actividades mientras imparten sus clases (figura 5).

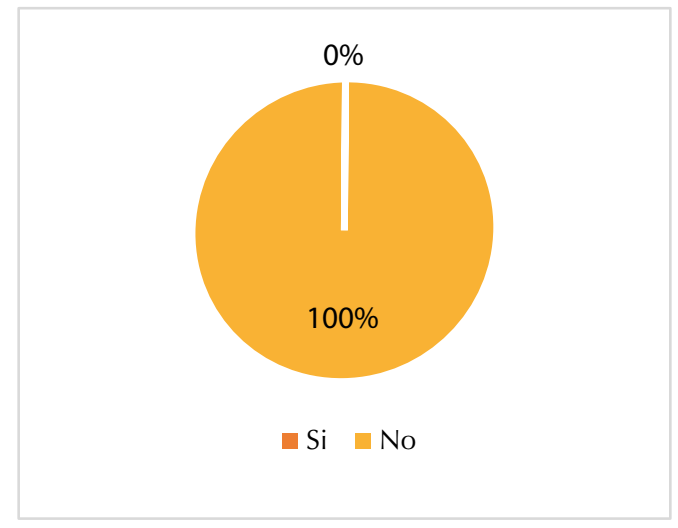

Figura 5. Pregunta para profesores:

¿Realiza otras actividades mientras está en clase?

Fuente: elaboración propia.

Por otro lado, para la mayoría de los estudiantes entrevistados las clases pasan más lento, sienten que duran más porque no existe el desplazamiento que se tiene en la universidad para ir de un salón a otro, siempre estamos en un mismo lugar que es la casa y llevar el ambiente del hogar es complicado. Algunas de las respuestas en las entrevistas visibilizan el cambio que ha tenido el paso del tiempo en clases en línea.

Las clases se vuelven más largas y tediosas por el hecho de solo ver fotografías y escuchar la voz del docente, es más propenso a sentir que el tiempo transcurre lento cuando uno no está totalmente concentrado que es lo que pasa en la virtualidad. (Entrevista a estudiante 3, 16 de noviembre 2020) 
Además, hay una constante en las respuestas que nos brindan los alumnos; ahora es más fácil distraerse, pues, mientras se asiste a clases en línea, se realizan otras actividades como trabajar, jugar videojuegos, ver las redes sociales, chatear, cocinar o hacer trabajos del hogar: "a veces hago cosas de la casa porque mi familia cree que las clases virtuales es solo sentarse y escuchar y que como uno está puede colaborar con algo" (cuestionario a estudiantes 15, 02 de noviembre 2020). En la figura 6 se ilustra dicha información.

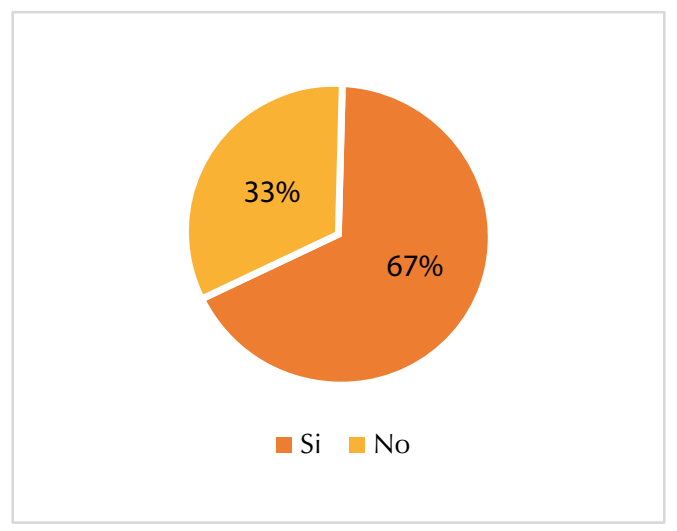

Figura 6. Pregunta para estudiantes: ¿Realiza otras actividades mientras está en clase?

Fuente: elaboración propia.

\section{Proxémica}

Para continuar el análisis, nos remitiremos a la proxémica. Este concepto analiza la relación que tenemos con el espacio que nos rodea, cómo nos desenvolvemos en él y cómo lo defendemos. El análisis de esta categoría arrojó datos similares en nuestras tres fuentes de datos. Las distancias son muy largas porque no nos podemos ver, estamos más que nunca dentro de lo que Goffman (1956) Ilama espacio personal, cuestión que resulta más complicada para los profesores porque los estudiantes no se muestran. Sin embargo, vivimos en una paradoja, estamos muy lejos, pero nos separa una pantalla que permite vernos tan cerca como queramos; con Zoom, podemos observar hasta los detalles más pequeños. Al revisar las clases grabadas nos dimos cuenta de la cercanía que presenta la cámara, pues en todas las clases (excepto en la clase 3B, Saberes y cotidianidades urbanas) los profesores se veían tan cerca que su rostro ocupaba el recuadro de la cámara y, en muchos casos, lo que más se mostraba era la frente.

Además, en la observación de las clases se constató que existe una proxémica léxica (Mandoki, 2006) entre los estudiantes y profesores, ya que, por su léxico, se puede intuir la cercanía que tienen. Por ejemplo, en clase 1B, Seminario de literatura colombiana, los estudiantes utilizan cierto tipo de proximidad con compañeros específicos al decir: "Me haces el favor, tú puedes compartir", "te quedó genial la exposición" (clase 1B, min 22:00). En otras ocasiones, esos mismos alumnos aumentan la distancia con otros compañeros $y$ mencionan: "Usted me puede hacer el favor, usted lo mencionó, como usted lo dice" (clase 1B, min 41:00). Al tener como referente la proxémica léxica que utilizan los estudiantes, podemos recrear una imagen de cómo sería el salón de clases (aunque no los conozcamos); es decir, pensar en quiénes estarían sentados juntos, qué grupos formarían o con cuáles compañeros hablarían más.

Por otro lado, para examinar los resultados de esta categoría tomamos en cuenta la pregunta en el cuestionario "¿Qué es lo que más extraña de las clases presenciales?". Allí se encuentra que los profesores y estudiantes extrañan la cercanía, el contacto y el afecto con los demás. En otras palabras, se echa de menos ver al otro, encontrarlo, saludarlo, abrazarlo, compartir el espacio del salón de clases sin que los separe una pantalla. Tomamos algunas respuestas para ejemplificar lo que hemos dicho.

\section{Profesores:}

La presencia con todo lo que implica: la nitidez de la voz, la cercanía, los gestos, las miradas, la risa, los suspiros, la posibilidad de tomarnos un café, entre muchas otras cosas. (Cuestionario a profesor 3 , 14 de noviembre 2020) 
La interacción personal, la corporalidad y el uso de espacios físicos de la universidad que crean otras formas de participación más allá de las clases con colegas y estudiantes. (Cuestionario a profesor 8, 14 noviembre 2020)

\section{Estudiantes:}

La interacción con mis amigos, eso era importante para que yo solidificara mis conocimientos. Generalmente antes de las clases siempre discutíamos los trabajos, hablábamos de las lecturas de libros que estamos adelantando y demás. (Cuestionario a estudiante 7, 12 de noviembre 2020)

Las miradas entre estudiantes y profesor, el ruido de los murmullos, salir por un tinto, reír con mis amigos después de clase. Extraño todo. (Cuestionario a estudiante 18, 14 de noviembre 2020)

\section{Paralenguaje}

Recordemos que el paralenguaje se refiere a los elementos sonoros que no tienen un significado verbal en general, estos le dan pistas al receptor para saber la intención de los mensajes. Así, en las grabaciones se evidencia que la voz ha tenido un papel primordial en las clases en línea, pues, cuando los micrófonos se apagan y las cámaras se cierran, solo escuchamos la voz de nuestro interlocutor; dicho de otra manera, nos volvimos totalmente auditivos. En las clases 1A (Seminario de literatura española) y 1B (Seminario de literatura colombiana) se pudo notar el trabajo que hace el profesor con su voz; adecúa el tono, sube la velocidad, realiza enfática acústica y fluxión acústica (Mandoki, 2006). Este trabajo es importante porque son clases en las que todo el tiempo se debe recitar, actuar o leer con diferentes tonos.

Además, al revisar las respuestas de las entrevistas y los cuestionarios terminamos de entender la relevancia de la modulación de la voz para los docentes. Estos consideran que, por medio virtual, la única manera de captar la atención de los estudiantes es por la voz. Además, siempre se piensa en los problemas que trae la virtualidad; se puede escuchar distorsionado o con eco, el volumen puede estar muy bajo, a causa de no ver los rostros no se sabe si la velocidad es la adecuada y muchas veces el hecho de estar tan cerca de un micrófono hace que se escuche enredado. Veamos la siguiente apreciación de un profesor:

Tal vez la voz es algo de lo que más he tenido que trabajar y es que si no puedo convencer, motivar o seducir por la cercanía, tengo que hacerlo a través de la voz y entonces se crean los silencios, los énfasis, el grito, la carcajada, el chiste o susurros como una manera de mantener activa esa comunicación y si lo hace uno en un escenario presencial, pues en este escenario de clases en línea es mucha mayor la necesidad de jugar con la voz, de trabajar con la voz, de conectarse con los tonos. (Entrevista a profesor 1, 03 de noviembre 2020)

Autores como Mehrabian (1972) y Birdwhistell (1970) estiman que la paralingüística tiene una importancia en el discurso de $33 \%$ a $55 \%$, premisa que se puede evidenciar en las respuestas de algunos estudiantes que afirman que el tono y volumen de la voz del profesor sí influyen en la disposición que puedan tener en clase porque "si es pasivo, neutral, lineal y no enfatiza es muy difícil prestar atención; si es muy monótono y tranquilo puede resultar aburrido" (entrevista a estudiante 4, 01 de diciembre 2020).

Por otro lado, en las clases en línea hay un nuevo actor en el escenario, se pone una máscara que no le permite emitir ningún tipo de sonido y causa terror en todos los asistentes, este es el silencio. Desde la perspectiva de los profesores el silencio en las clases en línea es doloroso y aterrador porque no tienen indicios para saber lo que significa y cortar con ese silencio es complicado. La respuesta de un docente en la pregunta " ¿Cómo controla los silencios en las clases en línea?", manifiesta lo siguiente sobre dicho momento: 
Ha habido momentos en este año en los que yo digo: “¿Queda alguien ahí? ¿Ya están todos dormidos?". Si queda alguien que se reporte y sigue el silencio y entonces digo: "No, no, esto se cortó, entonces yo voy a suspender el asunto". Inmediatamente ellos dicen: "No, profe. Aquí estamos". (Entrevista a profesor 1, 03 de noviembre 2020)

A raíz de lo anterior, se entiende la preocupación de los profesores por los silencios que se presentan en clases en línea, pues el silencio puede significar que un alumno no comprende el tema, no está dispuesto a responder una pregunta, no está de acuerdo con lo que se ha dicho o simplemente está pensando. Sin embargo, para descifrar todas estas situaciones es importante ver al estudiante y en situación de confinamiento estricto no es posible. Por otro lado, la cronémica interactiva (Sánchez, 2009) ha cambiado, en este caso el silencio dura más de lo esperado y ocupa mucho más tiempo de la clase.

También es necesario conocer la percepción de los estudiantes respecto al silencio en las clases, por ello preguntamos en las entrevistas: "¿Usted toma la palabra cuando se presentan silencios en la clase? ¿Lo ignora, escribe en el chat?". La mitad de los alumnos respondió que sí toma la palabra porque sienten vergüenza al ver que los profesores creen que nadie está atendiendo a la clase; otros enfatizaron en que participan solamente si saben del tema. La otra mitad de los entrevistados afirmó que no toma la palabra o lo hace solamente cuando los profesores preguntan directamente. Algunas respuestas de los estudiantes fueron las siguientes:

Ehh, no hacemos nada y se ponen bravos. Dicen como: "Ayyy, qué fastidio, ustedes no hablan". Pero igual yo no hago nada, sigo ahí normal, hay gente que sí le gusta hablar y responden. (Entrevista a estudiante 1, 02 de noviembre 2020)

Cuando entiendo sobre el tema sí me gusta participar, cuando veo que es pertinente decir algo me gusta y lo hago siempre y cuando entienda. Cuando estoy dispersa, no lo hago y me parece difícil porque me pongo en la posición de los profes y es complicado porque pues su público y sus estudiantes no cooperan con el diálogo de la clase. (Entrevista a estudiante 3, 16 de noviembre 2020)

\section{Factores ambientales}

Nuestra última categoría no verbal son los factores ambientales; estos cambiaron con el paso de la virtualidad a la presencialidad. Como lo menciona Goffman (1956), el medio cambió, ya no nos acompañan las sillas, la pizarra, los olores, el televisor o los árboles; estamos en casa, en nuestro espacio íntimo. En las grabaciones de las clases se puede ver que algunos profesores solo muestran su rosto y otros preparan su setting, es decir, se arreglan, utilizan accesorios y se posicionan en el lugar más cómodo. Un ejemplo es lo ocurrido en la clase 3B (Saberes ancestrales y cotidianidades urbanas): la profesora creó un escenario para la clase y adecuó su vestimenta a la temática que era realizar un ritual que conmemoraba el paso del sol; para ello utilizó "su mejor pinta", y preparó una mesa con frutas y granos que tenían la función de agradecer a la madre tierra por ese día especial. En esa línea, la información recolectada por las entrevistas y cuestionarios permite evidenciar que la mayoría de los profesores se prepara para sus clases como lo hacían presencialmente.

Claro que sí, yo me preparo físicamente, utilizo aretes, pañoletas, cadenas, abrigos por el frío entre otros. Considero, que hay que ponernos en actitud, y acompañada de café, igual hacía en la presencialidad. Eso da ánimos y transmite aliento, entusiasmo. (Cuestionario a profesores 2, 14 de noviembre 2020)

En el caso de los estudiantes, la rutina para tomar clase ha cambiado. Muchos afirman asistir a clases en pijama, acostados o en ropa con la que no saldrían de casa; manifiestan que preparan 
el setting cuando deben encender la cámara, de lo contrario no porque saben que nadie los está viendo, así que "las apariencias engañan" además de estar en pijama pueden estar realizando otras actividades:

No, para nada. Es un virtual de rutina, digamos tampoco era que yo lo hiciera básicamente por la universidad, lo hacía porque me parece que es casi una normal social. Yo tomo las clases con ropa de dos, tres días o de un día; realmente no me interesa por lo que yo no enciendo la cámara nunca. (Entrevista a estudiante 1, 02 de noviembre 2020)

\section{Sobre el uso de las TIC en el ciberespacio y la cibercultura}

Al realizar el análisis sobre el despliegue de las categorías no verbales en las clases virtuales, resulta necesario esclarecer cuál es el desarrollo de las TIC para llevar la CNV al aula. Como hemos dicho, la cibercultura crece en el ciberespacio y es allí donde se generan diferentes discursos que traducen las señales no verbales de la presencialidad por medio de las TIC. Así, al revisar las respuestas de los profesores respecto al uso de este tipo de tecnologías, pudimos evidenciar que estos tienen en cuenta que la Universidad Distrital Francisco José de Caldas no es una institución que tenga educación a distancia o virtual. Por tanto, no se tienen suficientes herramientas para realizar cursos en línea o explorar diferentes actividades, pues la universidad nunca se especializó en eso. Por esa razón, los docentes manifiestan que utilizan plataformas/aplicaciones básicas como PowerPoint, Meet, Zoom, extensiones de Google, y algunos exploran en el mundo del ciberespacio con aplicaciones como Canva, GeniaIly, Kahoot, Pownton, Animaton. Mientras que, para otros, la virtualidad ha sido muy complicada:

Bueno, la verdad, para mí, todo esto de la tecnología ha sido muy complicado, tuve que comprar computador y celular porque yo usaba uno de esos antiguos que solo tenía teclado, no era táctil ni nada de eso. Entonces tuve que comprar todo, al principio fue muy difícil porque yo no sabía usar nada y mis sobrinos me explicaban, digamos los estudiantes me decían que fulanito estaba esperando que yo lo aceptara en la llamada y yo no sabía cómo; entonces eso era inconveniente tras inconveniente y perdía mucho tiempo de la clase. (Entrevista a profesor 3, 22 de noviembre 2020)

El anterior fragmento es un claro ejemplo de lo complicado que ha sido para los maestros adaptarse a la virtualidad. Por eso, es prudente decir que, si la comunidad educativa (en general) no tiene suficiente conocimiento en el uso de las TIC, será complicado encontrar maneras de hacer visible la CNV. Esta situación es compleja, ya que, como lo menciona Lévy (2007), la educación virtual ha tenido un gran auge desde hace mucho tiempo y debería ser un compromiso de todas las instituciones el capacitar a toda la comunidad académica en los diferentes usos tecnológicos que provee el ciberespacio. Cuestión que, podemos suponer, no se ha realizado con los maestros de la LHLC, pues sus habilidades con las nuevas tecnologías son pocas. Algunos estudiantes mencionan que los docentes que se pueden desenvolver en este medio son los que se han especializado en la educación en tecnología, los demás no innovan con el uso de las TIC.

\section{Conclusiones}

A modo de conclusión, podemos declarar que conocer y analizar lo no verbal en el aula es importante porque conducirá a profesores y estudiantes a tomar consciencia de estos elementos de la comunicación y a utilizarlos con mayor frecuencia, pues, cuando se minimiza la CNV a la kinésica y a ser un apoyo de lo verbal, no se precisa su función en la interacción comunicativa. Esta primera conclusión nos parece vital, porque el análisis de los datos demuestra que para varios estudiantes y profesores la ausencia de las señales no verbales 
repercute en la enseñanza, y por eso se le presta más atención al uso de la voz. De este modo podemos afirmar que el supuesto que planteamos al inicio del documento sobre la ausencia y limitaciones que ha tenido la CNV se han corroborado por los datos obtenidos en este trabajo, ya que si la misma comunidad no reconoce el valor de la CNV es difícil que en las clases se note su importancia.

Por otro lado, a lo largo de este trabajo hemos intentado dar respuesta a la pregunta de investigación sobre cómo potenciar didáctica y pedagógicamente la $\mathrm{CNV}$ en las interacciones virtuales. Diremos que algunos aspectos que dan respuesta a esta pregunta son el uso de los emojis, imágenes de perfil o presentaciones virtuales didácticas (utilizar recursos que nos brindan las plataformas como letras que se mueven, cambian de color, hipertextos que dirijan a otras actividades discursivas). Así, se evidencia que las TIC también se sirven de la CNV. Por eso es importante que los profesores y los estudiantes reciban algún tipo de formación en el uso de las nuevas tecnologías, independientemente de que estos tiempos puedan terminar pronto, pues, es una realidad que ahora nos movemos por medios tecnológicos.

De esta manera, es fundamental que la perspectiva que tenemos de CNV evolucione junto a la tecnología; para esta finalidad hay que pensar en cada una de las maneras de traducir nuestros sistemas semióticos, que el aprendizaje sea multimodal y no se convierta en un sistema tradicional pero virtual. Es decir, no se trata de que la comunidad educativa conozca las diversas categorías no verbales que se presentan en el proceso de enseñanza/aprendizaje, sino de que realmente noten los beneficios de practicar este tipo de comunicación a la hora de proyectar sus discursos. En esta situación de virtualidad se piensa que la CNV se resume en la kinésica y por eso está exenta de participar en las clases en línea, pero hay varias maneras de llevar señales no verbales por medio de las TIC. ¿Por qué no pensar en incorporar lo táctil, olfativo o gustativo? Una apuesta de la CNV en las clases en línea debería ser no perder nuestra cotidianidad, como profesores: ¿Cómo trasladamos el paisaje, los sonidos, los olores, las texturas al espacio virtual?

\section{Reconocimientos}

Este artículo es producto de la investigación denominada "Comunicación no verbal y educación en tiempos de pandemia- Las veladas voces del cuerpo detrás de los cristales", realizada en la Licenciatura en Humanidades y Lengua Castellana y el semillero de investigación Hermeneia de la Universidad Distrital Francisco José de Caldas.

\section{Referencias bibliográficas}

Álvarez-Gayou, J. (2003). Cómo hacer investigación cualitativa. Fundamentos y metodología. Paidós.

Aristóteles. (1975). Poética. Gredos.

Aristóteles. (1990). Retórica. Gredos.

Bayes, M. (1970). An investigation of the behavioral cues of interpersonal warmth. Dissertation Abstracts Internationa, 31(4-B).

Birdwhistell, R. (1970). Kinesics and context. Trad. J. Desmonds. Editorial Gustavo Gili S. A.

Castañer, M. (2012). El poder del lenguaje no verbal del docente. Comprender e investigar la comunicación pedagógica. Milenio.

Cooper, P. (1988). Speech communication for the classroom teacher. 3a. ed. Gorsuch Scarisbrick Publishers.

Crystal, D. (2002). El lenguaje e internet. Trad. P. Tena. Cambridge University Press.

Davis, F. (2007). La comunicación no verbal. Alianza Editorial S. A.

Ferrero, M. y Martín, M. (2013). ¿La comunicación no verbal influye en el clima áulico? Editorial Biblos.

Gadamer, H. (1984). Verdad y método. Sígueme.

Gafner, S. (1977). Nonverbal Cues of Teacher Warmth as Perceived by Students. Dissertation Abstracts International, 38, 212.

Goffman, E. (1956). La presentación de la persona en la vida cotidiana. Ediciones Amorrortu. 
Goffman, E. (1971). Relaciones en público. Microestudios de orden público. Alianza Editorial.

Hernández, R., Fernández, C \& Baptista, P. (2014). Metodología de la investigación. McGraw- Hill.

Kvale, S. (2011). Las entrevistas en investigación cualitativa. Ediciones Morata.

Lévy, P. (2007). Cibercultura. Informe al consejo de Europa. Anthropos Editorial.

Mandoki, K. (2006). Practicas estéticas e identidades sociales- Prosaica 2. Siglo XXI Editores

Mehrabian, A. (1972). Nonverbal communication. Aldine-Atherton.
Poyatos, F. (1994). Paralenguaje, kinésica e interacción. La comunicación no verbal. Istmo

Scolari, C. (2008). Hipermediaciones. Elementos para una teoría de la comunicación digital interactiva. Gedisa.

Trager, G. (1958). Paralanguage: A first approximation. Studies in Linguistics, 13, 1-12.

Van Manen, M. (2003). Investigación educativa y experiencia vivida. Ciencia humana para una pedagogía de la acción y de la sensibilidad. Idea Books. 